\title{
Concrete hydration temperatures for the design of crack-width reinforcement in water-retaining structures - design values versus in-situ values
}

\author{
Matteo Angelucci ${ }^{1, *}$ \\ ${ }^{1}$ Building Services Unit (Water-retaining structures sub-unit) Aurecon Centre, 1 Century City Drive, 7441, Cape Town, South Africa
}

\begin{abstract}
Cracking in concrete can occur due to temperature changes at early ages and exposure to ambient temperature changes in the long term. Design codes and standards allow engineers to design for cracking by quantifying the effects of thermal variations into outputs such as limiting crack widths and reinforcement configurations. Design values given in these codes are however not fully understood by many users, may not be representative of recent developments in concrete materials technology and can potentially result in over-conservative designs. In this paper, concrete hydration temperatures were measured on site using a Thermocouple Data Logger and compared to values used in the project-specific design with the intention of providing a basis on which a database of temperatures representative of mixes commonly used in the South African industry may be compiled. Findings revealed that measured temperature values were around $30-50 \%$ lower than those given in design codes. Among the reasons identified for this is the fact that readily used design codes for crack-width design of water-retaining concrete structures in South Africa were compiled with data obtained from the use of $42.5 \mathrm{~N}$ cements, which may well have been quite different from the now more modern and readily available $52.5 \mathrm{~N}$ cements. Furthermore, design codes focus extensively on factors like binder content, binder type and formwork type, while the effects of other factors such as coarse aggregate type, coarse aggregate nominal size and construction sequence (which also play a significant role) are not quantified in the selection process of temperature values. Recommendations for further studies are made which aim to incorporate a wider variety of factors that affect development of thermal properties of concrete. This can allow members of the project team (engineer, contractor) to act during the relevant stages of design/construction of a project to mitigate thermal effects that can incur unwanted cracking.
\end{abstract}

\section{Background and Aim of Investigation}

Serviceability Limit State (SLS) design of reinforced concrete structures is concerned with ensuring that a structure under load can serve the function for which it was designed in a manner that is deemed appropriately safe for public use (from deflection criteria in suspended concrete beams and slabs, to sliding and over-turning in retaining walls). In water-retaining structures, one of the key serviceability requirements is designing concrete to control cracking. Cracking is inherent in concrete structures [10] and is caused by numerous intrinsic and extrinsic factors, among which are thermal variations in the structure and concrete mix constituents [2]. Thermal variations can arise due to temperature changes in the concrete section at early ages and exposure to ambient temperature changes in the long term, all of which can lead to cracking in the presence of restraint $[2,3,7]$. One of the standards that is commonly used in the design of water-retaining structures is the British Standard BS 8007:1987 for the design of concrete structures for retaining aqueous liquids. In this standard, temperature changes are presented as values that designers can use to quantify the effects of thermal variations into desirable outputs like limiting crack widths and reinforcement configurations. The temperature values present in the code are dependent on a variety of factors, such as binder content, section thickness and type of formwork used. However, the values that are present in the code are based on empirical data that is not representative of recent developments in concrete mix design technology. Furthermore, current industry trends like using high minimum cement contents and increasing structural section sizes have been shown to result in high heats of hydration that often lead to reinforcement designs that are more conservative $[1,10]$.

In the proposed investigation, the aim was to measure concrete temperatures on site and compare them to values used in design. Firstly, this would aim to give an indication of how closely values commonly used in design represented actual values measured in-situ. In the long-term, the findings would provide a basis on which a

* Corresponding author: Matteo.Angelucci@aurecongroup.com 
database of temperatures representative of commonly used mixes may be compiled.

With an agreement between project director and client, the Aurecon Project that was selected as the pilot project for the measuring of in-situ concrete temperatures was the upgrading of the Stellenbosch Wastewater Treatment Works.

This paper begins with a literature review that gives a brief contextualisation of the effects of temperature variations on the cracking of concrete and the current industry design trends, thus identifying a need for a comparison between design temperature values and actual temperature values measured in-situ. The literature overview is followed by a description of the measurement apparatus and on-site testing procedure, presentation and discussion of the results. Lastly, a conclusions and recommendations section proposes further research that can be carried out based on the obtained results.

\section{Literature Review}

When concrete sets, the chemical reaction liberates heat as the cement and water react with one another in the hydration process $[1,2]$. This heat of hydration raises the temperature of the constituent materials in the concrete mixture [5]. At first, the concrete expands because the heat developed in the section exceeds the rate at which it can be dissipated, but the expansion is soon followed by contraction as the concrete cools down to ambient temperature. Depending on the size and thickness of the section, as well as the mixture composition, this can occur within a few days or several weeks. In thin sections and slender structures or in structures with moderate binder contents, the heat generated is rapidly dissipated through the adjacent surfaces. In larger structures where the core of the concrete is approximately $1 \mathrm{~m}$ from a surface, or in structures with high binder contents, the heat generated in the core is not dissipated quickly enough and a temperature differential develops between the core and the surface zones $[2,5,7$, 8]. It is this temperature differential, caused by the heat of hydration, that is the predominant factor contributing to the potential for early-age thermal cracking in concrete structures $[6,8]$.

When exposed to hot and cold ambient temperatures over time, concrete members will expand and contract respectively [7]. In the absence of restraint, the resulting volume changes would be of little consequence in the long-term, but in practice there is inevitably some restraint that occurs due to, among other factors, temperature differences within the section, length of time in which formwork is left in place, presence of reinforcement and construction joints arising from the sequencing of construction $[5,6]$. Hence, concrete will continue to crack if the bulk volume change that occurs because of temperature variations is restrained [7]. Cracking in reinforced concrete members is not to be regarded as a defect. The very basis of reinforced concrete design is that reinforcement is provided to control cracking as concrete is weak in tensile strength
[10]; cracking is an integral part of reinforced concrete, but becomes a problem when the durability, serviceability or appearance of the structure are impaired by the cracking. For example, in the design of containment structures, excessive or uncontrolled cracking can lead to the unwanted leakage of water or radiation into the surrounding environment $[2,10]$.

Thermal variations in concrete can arise not due to temperature changes in concrete sections at early ages, but also due to exposure to ambient temperature changes in the long term, all which can lead to cracking in the presence of restraint $[2,3,7]$. In BS 8007:1987, crackwidth calculations are based on a series of parameters, selected to control cracking by minimising early thermal movement and reducing movement restraint [2, 10]. Intrinsic factors include the following:

- Geometry (section thickness, aspect ratio).

- Binder type.

- Concrete mix proportions (binder content and aggregate type).

Extrinsic factors include the following:

- Formwork and insulation.

- Ambient conditions and placing temperature.

- Provision of construction joints.

- Construction sequence.

- Movement joints.

Through selection of the above parameters, the effects of thermal variations in the presence of restraint can be converted into desirable outputs like limiting crack widths and reinforcement configurations. However, certain issues arise from the use of these design values $[1,10]$ :

- The information listed above, on which selection of temperature values is based, is usually not available during design. Conservative assumptions are often made that are not adjusted later when the information becomes available (higher binder contents lead to higher design temperatures and higher reinforcement quantities).

- The values present in most modern standards are based on empirical data that does not account for the latest developments in concrete mix technology (new cements and binders).

- Recent trends in industry (increasing the size of concrete sections, high minimum binder contents and low water/binder ratios) can result in unnecessarily high heats of hydration.

Considering this, the use of design values based on conservative assumptions and old cements/binders can result in temperatures being used in calculations that are higher than those occurring on site, resulting in conservative designs. Possible consequences of this can be increased material costs due to higher binder and reinforcement quantities, as well as delays in construction programme due to unplanned and expensive crack repairs. With a basic understanding of the effects that temperature variations have on the cracking of concrete, the engineer can make design decisions that 
can potentially save time, effort and money [1]. Based on this literature review, it was deemed necessary to measure actual in-situ values and compare them to values used in design to assess whether designs could be improved or optimised. This would serve as a "pilot" project, as well as a solid foundation for the compilation of a database of temperature values for concrete mixes used in different projects.

\section{Measuring Equipment and Procedure}

The equipment that was used for testing needed to be cost effective, but also have a degree of accuracy that would be suitable for the intended purpose. After consultations with Mr George Evans (PPC Cement) and Professor Mark Alexander (University of Cape Town), the choice was made to use a Thermocouple Data Logger to measure on-site concrete temperatures. The logger was a S220-T8 with 24-gauge type "K", PVC coated $\mathrm{NiCr}$ thermocouple (TC) wire with mini-type $\mathrm{K}$ plugs for digital recording.

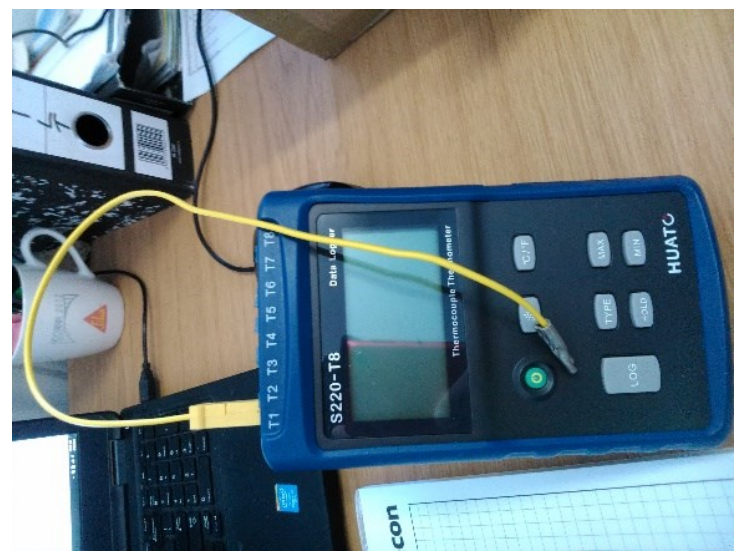

Fig. 1. Data logger and thermocouple set for measuring concrete temperatures on site.

The wire was stripped at both ends for each set of TC wires. The measuring end was "closed" with a crimped ferrule and tied to the rebar with plastic ties to ensure that there would be no electrical contact between $\mathrm{TC}$ and rebar that could alter the readings. The other end of the TC wire was connected to the mini-type $\mathrm{K}$ plug and plugged into the logger, which then recorded measurements. Figure 1 displays a simplified set-up of the equipment used.

The choice of the data logger model was motivated by the fact that this was an 8-channel digital data logger that allowed recorded data to be downloaded to an external device (laptop or computer) to then export it to other software (MS Excel) for plotting the results. The main objective was to measure temperatures in different points along the concrete section for a given pour, to obtain a temperature profile for each measurement point. The new Membrane Biological Reactor was chosen to conduct the temperature measurements for the following reasons:

- The structural design of bases and walls had been carried out in accordance with crack-width requirements as set out in BS 8007:1987. This provided ample choice of design temperature values for comparison with measured in-situ values.

- Testing equipment could be procured in good time since site operations for the new bioreactor were behind schedule due to excavation time being lengthened by the presence of a large rock outcrop.

A schematic of the chosen measurement points for bases and walls is given in Figures 2 and 3 respectively.

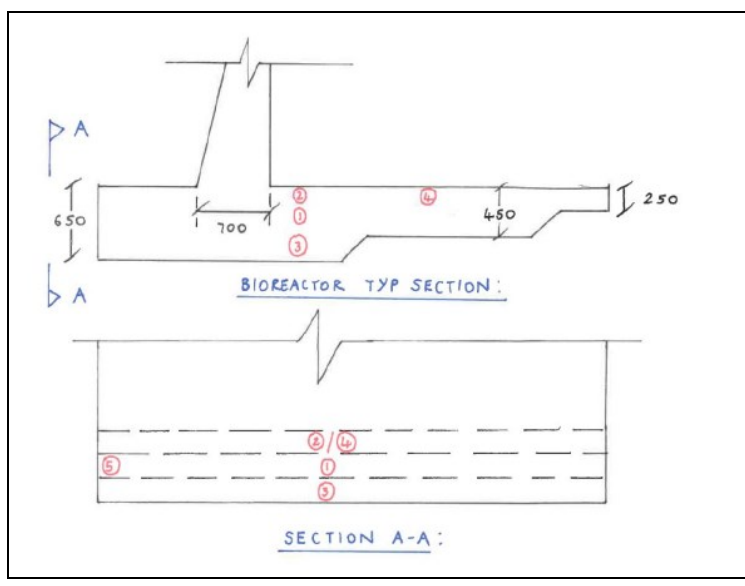

Fig. 2. Base schematic for concrete temperature measurements.

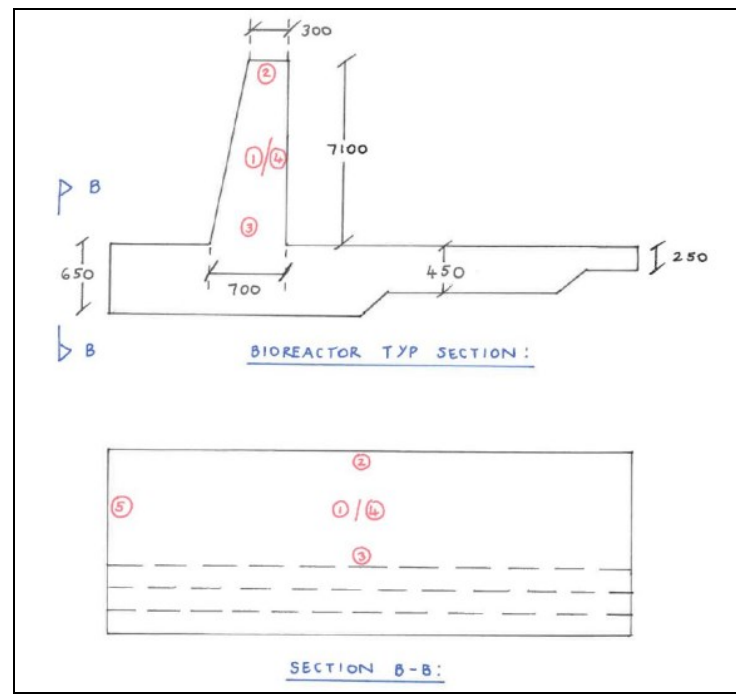

Fig. 3. Wall schematic for concrete temperature measurements.

For each base, 5 points were selected that were expected to yield differences in temperature values due to changes in sections and/or proximity to surface/ground/shutters. The points shown on Figure 2 are described below:

- Core of 650 thk RC base at mid-panel (Point 1).

- Top cover zone of 650 thk RC base at mid-panel (Point 2).

- Bottom cover zone of 650 thk RC base at midpanel (Point 3).

- Core of 450 thk RC base at mid-panel (Point 4) 
- $\quad$ Side shutter cover area of 650 thk RC base at midpanel (Point 5).

Similarly, for each wall, 5 points were selected that were expected to yield differences in temperature values due to changes in section thickness and/or proximity to construction joints/shutter faces/top surface. The points shown on Figure 3 are described below:

- $\quad$ Core of tapering wall at mid-height (Point 1).

- Core of tapering wall at top cover zone (Point 2).

- Core of tapering wall at kicker/bottom construction joint (Point 3).

- Inside shutter cover zone of tapering wall at midheight (Point 4).

- Side shutter/stop end cover zone of tapering wall at mid-height (Point 5).

The table below summarises the constituents of the concrete mix that was used for the water-retaining structures on this project.

Table 1. Mix Design Parameters.

\begin{tabular}{|c|c|}
\hline Design Strength (MPa) & 35 \\
\hline Water/Binder Ratio & 0.48 \\
\hline Water Content $\left(\mathrm{L} / \mathrm{m}^{3}\right)$ & 165 \\
\hline HSC Afrisam $52.5 \mathrm{~N}\left(\mathrm{~kg} / \mathrm{m}^{3}\right)$ & 242 \\
\hline PPC Slagment (kg/m³) & 100 \\
\hline $27 \mathrm{~mm}$ Granite Stone $\left(\mathrm{kg} / \mathrm{m}^{3}\right)$ & 1130 \\
\hline Crusher Sand $\left(\mathrm{kg} / \mathrm{m}^{3}\right)$ & 403 \\
\hline Dune Sand $\left(\mathrm{kg} / \mathrm{m}^{3}\right)$ & 392 \\
\hline $\begin{array}{l}\text { Chryso Omega } 103 \\
\text { Admixture }\left(\mathrm{L} / \mathrm{m}^{3}\right)\end{array}$ & 4.13 \\
\hline Target slump (mm) & $100 \pm 25$ \\
\hline
\end{tabular}

It was decided that 3 bases and 3 walls would be measured for the experimental programme to enable analysis and drawing of possible conclusions based on a large enough sample of readings. For each base, thermocouples were installed just before the pours after final inspection. For each wall, the installation of thermocouples usually took place the day before casting, before closing of the shutters. Temperatures were logged every 30 minutes for a period of 7 days.

\section{Results}

The bioreactor bases on which temperature recordings were done were cast separately on the following dates:

- $\quad$ Base $1-22^{\text {nd }}$ April 2016.

- $\quad$ Base $2-5^{\text {th }}$ May 2016.

- $\quad$ Base $3-30^{\text {th }}$ May 2016

The following figures show the recorded data for each base. Results are summarised below and are discussed in Section 5.

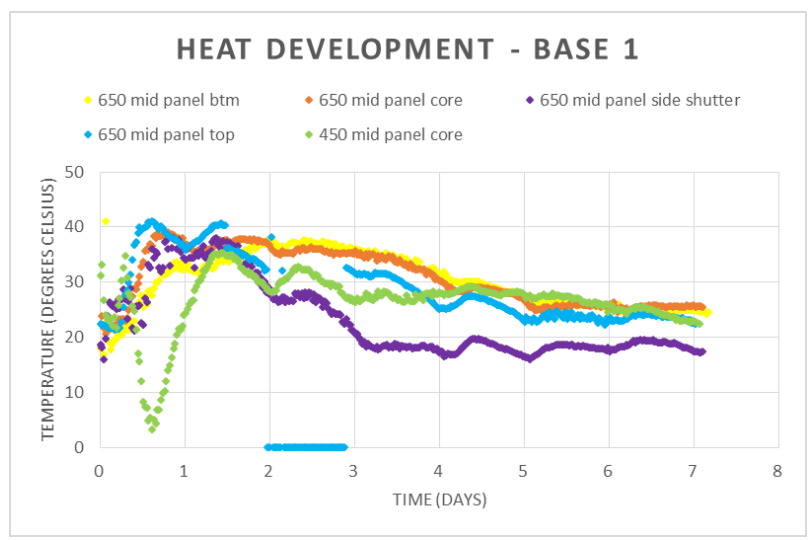

Fig. 4. Temperature development - Base 1 .

Temperatures measured in the first base showed a general increasing trend during the first day to approximately $40^{\circ} \mathrm{C}$, after which they tapered off to a value of $20^{\circ} \mathrm{C}-25^{\circ} \mathrm{C}$ at 7 days. One of the thermocouples (650 mid-panel top) experienced a temporary malfunction over the weekend, which can be seen in the graph as the $0^{\circ}$ line between days 2 and 3 , before it started working again the following Monday morning. Another thermocouple (450 mid-panel core) showed an initial, unexpected decrease in temperature for the first half-day, before the temperature rose again to reach a maximum and then taper off. Peak temperatures at each point were close to one another, but, as temperatures tapered off, the biggest drop was recorded at the thermocouple located at the side-shutter face.

Similar results were obtained in Base 2, where concrete temperatures increased to $40^{\circ} \mathrm{C}$ during the first day (peak temperatures were close to one another, with the highest recorded at the $650 \mathrm{mid}$ panel and $450 \mathrm{mid}$ panel cores) before tapering off again to between $20^{\circ} \mathrm{C}$ and $25^{\circ} \mathrm{C}$. The 650 mid-panel side-shutter thermocouple displayed the second lowest temperature after 7 days, with the lowest being recorded at the 450 mid-panel core. Similar results were obtained for Base 3, but with peak temperatures being around $35^{\circ} \mathrm{C}$ and tapering off to between $10^{\circ} \mathrm{C}$ and $20^{\circ} \mathrm{C}$. 


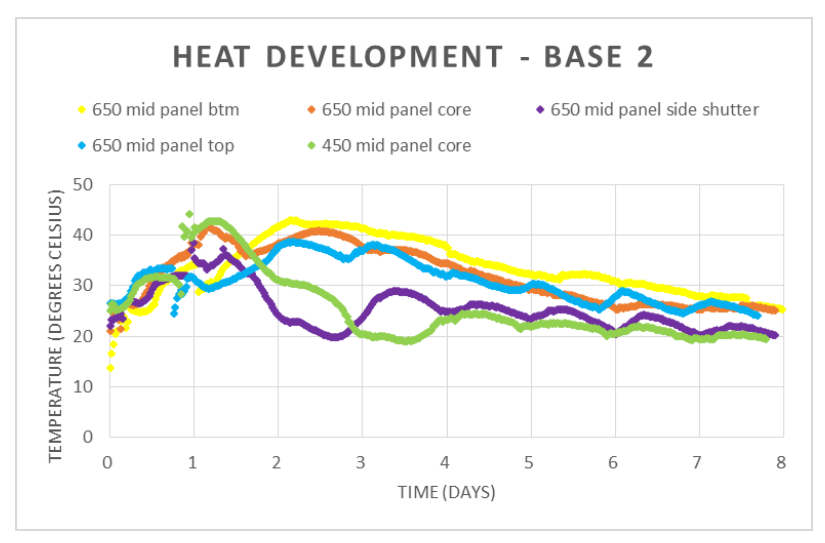

Fig. 5. Temperature development - Base 2 .

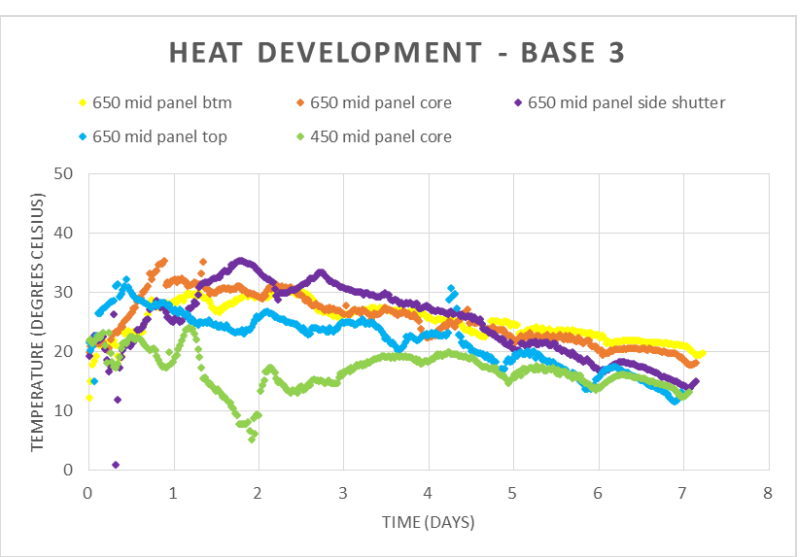

Fig. 6. Temperature development - Base 3 .

The bioreactor walls from which temperature recordings were taken were cast separately on the following dates:

- $\quad$ Wall $1-1^{\text {st }}$ July 2016.

- Wall $2-17^{\text {th }}$ August 2016.

- $\quad$ Wall $3-5^{\text {th }}$ September 2016.

It must be noted that Wall 2 was tested/recorded three times due to complications in the measuring procedure; the first time, three of the five thermocouples were accidentally unplugged by the Civil Contractor during pouring operations, hence the readings were scrapped. The second time, the data logger malfunctioned and was sent back to the supplier to be repaired, rendering that set of readings also unusable. During the third attempt at recording, I identified the day after the pour that none of the installed thermocouples had successfully recorded temperatures during Day 1. I stopped recording and restarted it immediately, but found that upon restarting, one of the thermocouples (bottom wall centre) was not working, regardless of which channel it was plugged into. Since the rest of the thermocouples continued working, I decided to continue with the recording so that the set of readings would be usable. This is the only wall where there are no readings for bottom wall centre TC and where readings are only plotted from Day 1. The following figures show the recorded data for each wall, and are discussed in Section 5.

Trends in the walls were more difficult to identify. In Wall 1 , the concrete temperature generally increased to $30^{\circ} \mathrm{C}$ after the first day, and then reduced to between $10^{\circ} \mathrm{C}$ and $20^{\circ} \mathrm{C}$. The obtained readings showed that the highest peak occurred after 1 day at the thermocouples near the kicker joint between base and wall (bottom wall centre) and at wall mid-height near the stop-end (midwall stop-end). Wall 1 results also showed a much higher variation in readings, with clear local peaks and troughs over 24-hour periods throughout the 7-day duration of measurement.

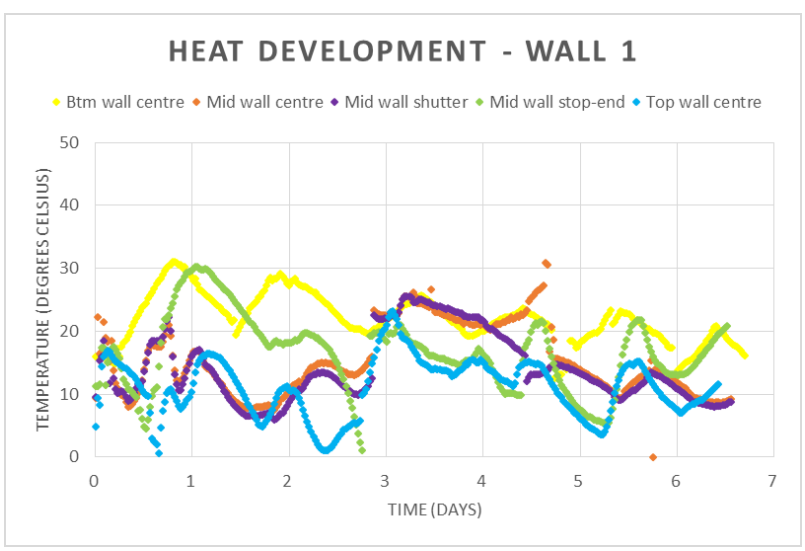

Fig. 7 Temperature development - Wall 1 .

In Wall 2, the readings showed that the highest peak occurred at mid wall centre at around 1 day after the pour. Local peaks and troughs in this wall were not as prominent as in Wall 1, but were visible at the top wall centre and at the mid wall stop end.

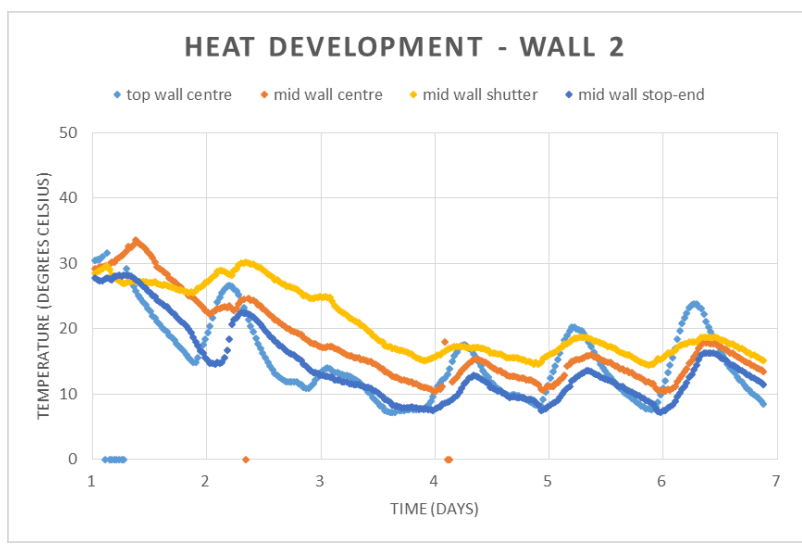

Fig. 8. Temperature development - Wall 2.

In Wall 3, a clear reduction in temperature over the 7-day measurement period was observed. Early measurements showed a clear variation over the first day. Decreases in temperature were quite clear before temperatures started increasing again towards peaks of around $40^{\circ} \mathrm{C}$, and then reduced again to taper off at around $20^{\circ} \mathrm{C}$ to $30^{\circ} \mathrm{C}$. The peaks were recorded in the top wall centre and mid wall shutter thermocouples, while clear peaks and troughs over 24-hour periods were again visible. 


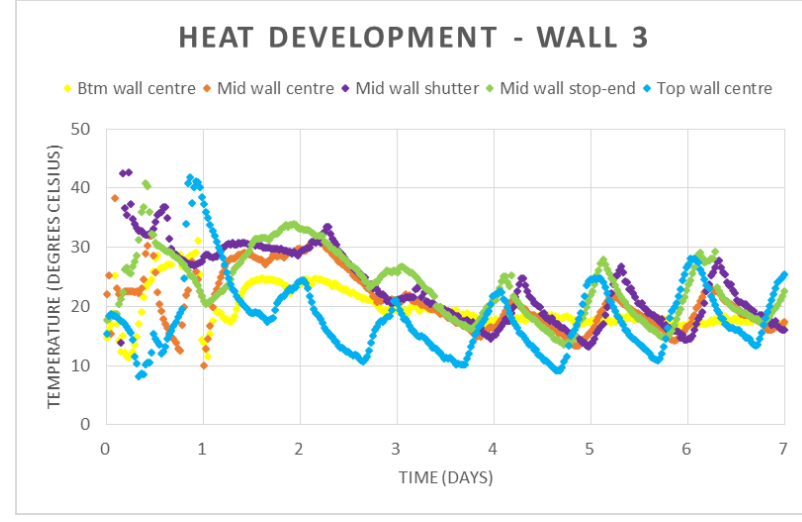

Fig. 9. Temperature development - Wall 3.

Wall 3 also made it difficult to identify any clear trends, except for a clear reduction in temperature over the 7-day measurement period. Early measurements showed a clear variation over the first day. Decreases in temperature were quite clear before temperatures started increasing again towards peaks of around $40^{\circ} \mathrm{C}$, and then reduced again to taper off at around $20^{\circ} \mathrm{C}$ to $30^{\circ} \mathrm{C}$. The peaks were recorded in the top wall centre and mid wall shutters thermocouples, while clear peaks and troughs over 24-hour periods were again visible.

\section{Discussion of Results}

The temperature profile of all 3 measured bases showed similar results, with peaks in temperatures occurring at the same period of around 1 day after commencement of pour. The peaks that occurred at different points in the section were all close to one another, which was contradictory to the expected trend that higher temperatures would occur at the core of the 650-thick portion. The aspect ratio (plan dimensions/thickness) of the bioreactor bases was fairly high, hence a large surface area was exposed to the elements (sunlight and wind); this could have impacted the heat development in the core and the heat dissipation to the rest of the section i.e. the development of hydration heat in the core did not occur quickly enough to offset dissipation to the rest of the section and to the atmosphere through the top surface, thus resulting in a small difference in peak values throughout the section. This also coincides with observations made in previous publications [2, 10]. It was also observed for the bases that the temperatures recorded at the thermocouple installed near the side shutter face were generally the ones that reduced more significantly over the 7-day measurement period. This made sense since this is the point in the bases that would have experienced the biggest "shock" in temperature after the stripping of formwork.

Trends in the walls were not as straight-forward. While peaks in recorded hydration temperatures generally occurred 1 day after pour, there was no clear trend as to which points in the wall section exhibited the highest peak since all the peaks occurred at different points for each wall. It was also observed that there was generally a much higher scatter in the measured data in the early periods of recording (from 0 to 1 day), though it is unclear as to why. This was observed in Walls 1 and 3 , but not in Wall 2, likely due to a temporary malfunction in the data logger as explained in Section 4.

\subsection{Concrete temperatures in crack-width design}

In BS 8007:1987, crack-width calculations are based on a series of parameters, among which is the design parameter $\mathrm{T} 1$. This parameter is defined as the difference between concrete peak hydration temperature and concrete ambient temperature [11]. The selection of this parameter in the design process is dependent on a variety of intrinsic and extrinsic factors, as can be seen from figures 10 and 11 . The value of $\mathrm{T} 1$ used in design can differ greatly according to what assumptions are made for parameters that are not yet known during design. It is also worth noting that if we compare the $\mathrm{T} 1$ values obtained by using BS 8007:1987 to those obtained using CIRIA C-660 for a given concrete mix cast in the same type of formwork, the values are generally within $4^{\circ} \mathrm{C}$ $5^{\circ} \mathrm{C}$ of one another. Crack-width design of RC structures in the Stellenbosch project was done in accordance with BS 8007:1987 to a limiting crack-width of $0.2 \mathrm{~mm}$, but $\mathrm{T} 1$ values were chosen from CIRIA C-660 since it was the more recent of the two documents. The theoretical design value of $\mathrm{T} 1$ for bases and walls was then compared to the value for $\mathrm{T} 1$ obtained from in-situ measurements.

\begin{tabular}{|c|c|c|c|c|c|c|}
\hline \multirow{4}{*}{\begin{tabular}{|c|}
1 \\
$\begin{array}{c}\text { Section } \\
\text { thickness }\end{array}$
\end{tabular}} & \multicolumn{3}{|c|}{2} & \multicolumn{3}{|c|}{3} \\
\hline & \multicolumn{6}{|c|}{ Walls } \\
\hline & \multicolumn{3}{|c|}{$\begin{array}{l}\text { Steel formwork: OPC content, } \\
\mathrm{kg} / \mathrm{m}^{3}\end{array}$} & \multicolumn{3}{|c|}{$\begin{array}{l}18 \mathrm{~mm} \text { plywood formwork: OPC content, } \\
\mathrm{kg} / \mathrm{m}^{3}\end{array}$} \\
\hline & 325 & 350 & 400 & 325 & 350 & 400 \\
\hline $\mathrm{mm}$ & ${ }^{\circ} \mathrm{C}$ & ${ }^{\circ} \mathrm{C}$ & ${ }^{\circ} \mathrm{C}$ & ${ }^{\circ} \mathrm{C}$ & ${ }^{\circ} \mathrm{C}$ & ${ }^{\circ} \mathrm{C}$ \\
\hline 300 & $11^{*}$ & $13^{*}$ & $15^{*}$ & 23 & 25 & 31 \\
\hline 500 & 20 & 22 & 27 & 32 & 35 & 43 \\
\hline 700 & 28 & 32 & 39 & 38 & 42 & 49 \\
\hline 1000 & 38 & 42 & 49 & 42 & 47 & 56 \\
\hline
\end{tabular}

Fig. 10. Typical values of $\mathrm{T} 1$ for CEM I concretes (BS 8007:1987).

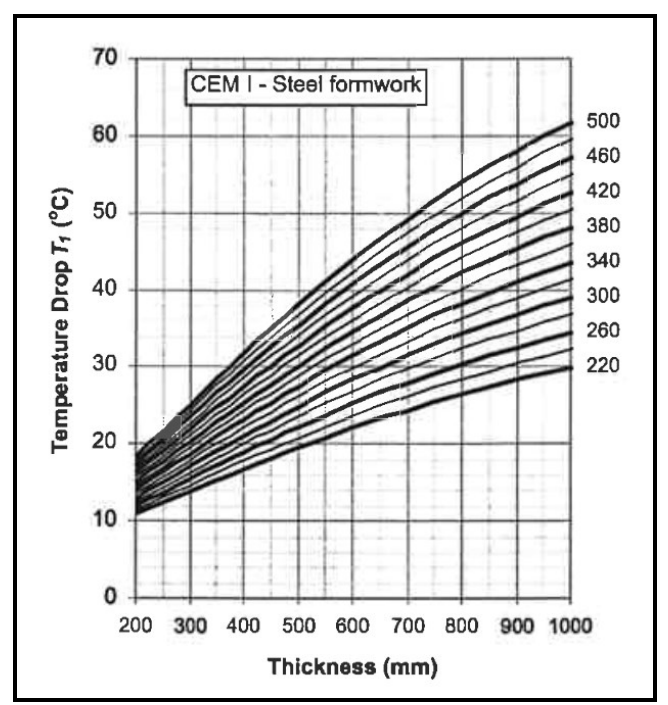

Fig.11. Typical values of $\mathrm{T} 1$ for CEM I concretes for walls using steel formwork (CIRIA C-660:2007). 
For a $650 \mathrm{~mm}$ thick slab on ground, CIRIA C-660 explains that the $\mathrm{T} 1$ value may be obtained by estimating the value for a wall cast into steel formwork which has a thickness of 1.3 times that of the slab i.e. $650 \times 1.3=845$ $\sim 850 \mathrm{~mm}$. With a mix consisting of $342 \mathrm{~kg} / \mathrm{m}^{3}$ binder, and treating the binary blend of CEM I and Corex Slag (CS) as a $100 \%$ CEM I mix, the theoretical design value obtained for T1 for the bioreactor base is around $40^{\circ} \mathrm{C}$ (see Figure 11). For the tapering walls, the larger section thickness was at the joint between wall and base. For the same concrete mix and a section thickness of around $700 \mathrm{~mm}$ at the base of the wall, the highest $\mathrm{T} 1$ value for the bioreactor wall is around $35^{\circ} \mathrm{C}$. For the smallest section of the tapering wall being $300 \mathrm{~mm}$ (the value will reduce as the section of the wall reduces with increasing height), the estimated $\mathrm{T} 1$ value is around $20^{\circ} \mathrm{C}$.

Calorimetric testing on a representative sample of the mix used for the project was also conducted by the School of Civil and Environmental Engineering at the University of the Witwatersrand to determine some key characteristics of the concrete mix [12]. The test involved casting a one-litre sample of concrete and, immediately after casting, placing it in a water bath such that a stationary pocket of air separates the sample from the water. A signal from a temperature probe placed in the sample is monitored by a programmable logic controller (PLC) which switches a heater in the water bath on and off to maintain the water at the same temperature as the concrete sample [13]. This ensures that there is no exchange of heat between the concrete sample and the surrounding environment. The pocket of air around the sample is important because it dampens any harmonic responses between the sample and the water temperatures as a result of the measurement sensitivity of the thermal probes. The test was run over a period of 7 days, by which time the rate of heat evolution is too low to be detected as a temperature difference by the thermal probes. The main results are summarised in the table below (note $-t_{2}$ o hours, denoted as maturity time, is defined as the equivalent time of curing at a constant temperature of $20^{\circ} \mathrm{C}$ and is useful for comparing cements that have been hydrated at different temperatures):

Table 2. Summary of hydration properties of Stellenbosch WWTW concrete mix.

\begin{tabular}{|c|c|c|}
\hline $\begin{array}{c}\text { Adiabatic } \\
\text { temperature } \\
\text { rise }\end{array}$ & ${ }^{\circ} \mathbf{C}$ & 46.9 \\
\hline $\begin{array}{c}\text { Total heat } \\
\text { evolved }\end{array}$ & $\mathbf{k J} / \mathbf{k g}$ & 350.2 \\
\hline $\begin{array}{c}\text { Maturity } \\
\text { time to reach } \\
\text { total heat } \\
\text { plateau }\end{array}$ & $\mathbf{t}_{20}$ hours & 312.7 \\
\hline $\begin{array}{c}\text { Peak heat } \\
\text { rate }\end{array}$ & $\mathbf{W} / \mathbf{k g}$ & 1.61 \\
\hline
\end{tabular}

Important results to note from the above are [13]:

- Peak heat rate of $1.61 \mathrm{~W} / \mathrm{kg}$ of binder, which is a relatively low value [16] and thus beneficial in structures where thermal cracking should be mitigated.

- Time of $21.2 t_{2}$ o hours taken for the mix to reach peak heat rate, which generally coincides with theoretical value of 20 hours to attain the peak heat rate value [16]. This value also coincides with the \pm 24 hours where the peak in-situ temperatures were recorded during the on-site measurement periods.

To have a comparative value for the on-site measurements for bases and walls to relate to theoretical and experimental temperature values, the in-situ values of T1 were obtained by subtracting the following temperatures:

- For bases, the temperature measured at the sideshutter face (closest approximation of ambient concrete temperature) was subtracted from the temperature obtained at the $650 \mathrm{~mm}$ thick core.

- For walls, the temperature measured at the top centre of the wall (closest approximation of ambient concrete temperature due to the point being closer to the surface and due to smallest section thickness) was subtracted from the temperature obtained at the bottom centre of the wall.

Figures 12 and 13 show plots of $\mathrm{T} 1$ values vs time for the bases and walls.

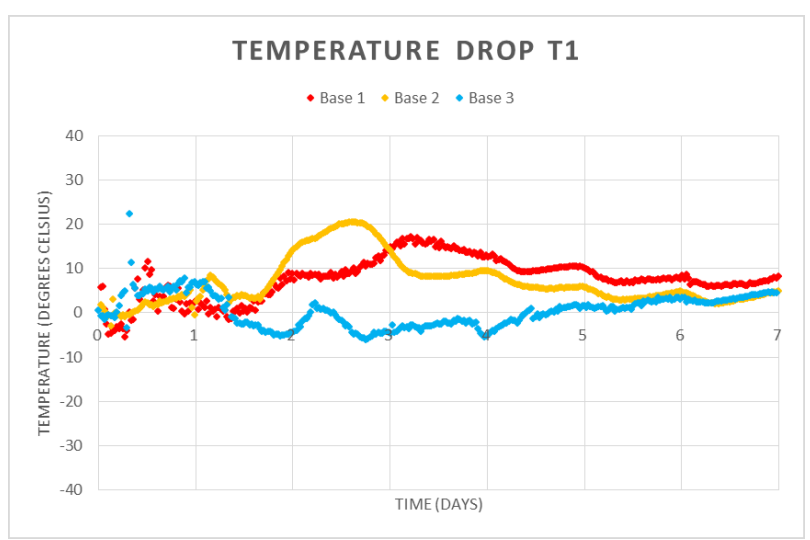

Fig. 12. Temperature change (T1) values for bases.

It can be seen that, in all the bases, the value of $\mathrm{T} 1$ (here defined as core temperature minus the temperature at side shutter face) did not reach the expected design values, with in-situ numbers not exceeding $20^{\circ} \mathrm{C}$ for all bases. Furthermore, observations made from the testing conducted by the School of Environmental and Civil Engineering [13] showed that during the heat evolution, two peaks could be observed with respect to maturity time. This was attributed to the presence of Corex Slag in the mix, which is a latent hydraulic binder and whose hydration reaction is promoted by the presence of the cementing reaction between cement and water [14]. This could be the reason why the highest temperature drop T1 was observed in all 3 bases after the 1-day mark, attributed to the longer reaction time needed for the Corex Slag to start taking part in the cementing reaction. 
Similar observations can be made for the walls. Insitu temperature values for the walls generally did not exceed $25^{\circ} \mathrm{C}$, which approximated more closely the lowest estimated $\mathrm{T} 1$ design value of $20^{\circ} \mathrm{C}$ (characteristic of the smallest section at the top of the wall) than the highest $\mathrm{T} 1$ value of $35^{\circ} \mathrm{C}$.

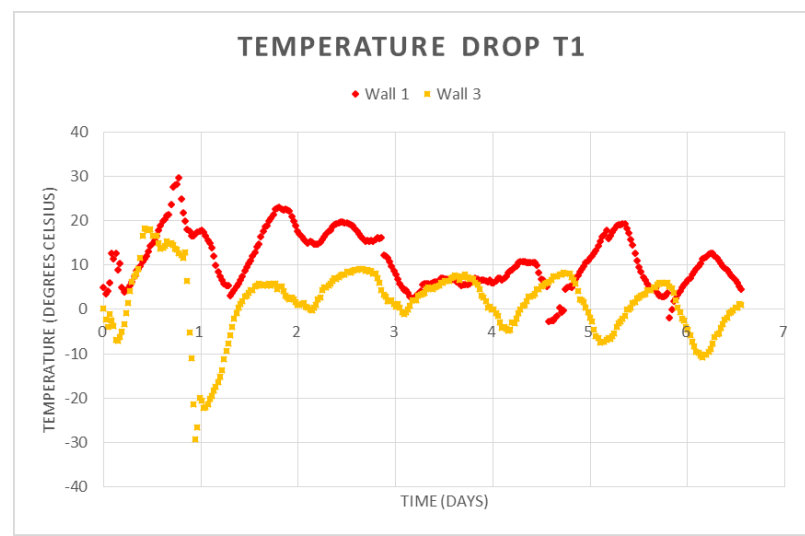

Fig. 13. Temperature change (T1) values for walls.

Upon analysis of the obtained data, there are some possible reasons why the measured peak $\mathrm{T} 1$ values were lower than those present in codes and standards used in design, some of which are listed below:

- The values present in BS 8007 are only representative of singly blended mixes (100\% CEM I). The values found in CIRIA C-660 also account for binary blends containing different levels of both Ground-granulated Blastfurnace Slag (GGBS) and Fly Ash (FA), extenders that knowingly reduce hydration temperatures. Since there are no values present in either code representing the mix used for the Stellenbosch project (cement/Corex Slag bend), an assumption was made that the thermal characteristics of a cement/Corex Slag blend are similar to a $100 \%$ CEM I mix. This could be conservative i.e. it is possible that the Corex Slag could have similar effects on concrete thermal behaviour to GGBS.

- Both BS 8007 and CIRIA C-660, which are readily used for crack-width design of concrete structures, were compiled with data obtained from the use of $42.5 \mathrm{~N}$ cements, which may well have been quite different from the now more modern and readily available $52.5 \mathrm{~N}$ cements.

- The thermal behaviour of the concrete mix used for the Stellenbosch project was designed with granite as coarse aggregate, which has one of the lowest coefficients of thermal expansion compared to other readily available South African aggregates. This will thus become a characteristic of the concrete mixture that granite is a constituent of, thus potentially mitigating the effects of thermal cracking. The selection of $\mathrm{T} 1$ values from design codes does not quantify this effect.

- The size of the coarse aggregate is also likely to have played a role. In a unit volume of concrete with the largest nominal particle size of $27 \mathrm{~mm}$, there was less paste than in a unit volume made with more conventional, smaller nominal particle size $(13 \mathrm{~mm}-$ $19 \mathrm{~mm})$. The selection of $\mathrm{T} 1$ values from design codes also does not quantify this effect.

- The adiabatic conditions that were adopted while the test was conducted were quite isolated and ensured that the cementing reaction could continue unhindered. This was potentially not the case when it came to site conditions, due to the presence of "heat sinks" such as construction joints like the kicker joint, which may have caused the dissipation/loss of more heat. Actual conditions on site therefore seemingly play a larger role than current design codes allow for.

\section{Conclusions and Recommendations}

The experimental programme conducted on site showed that temperatures measured resulted in $\mathrm{T} 1$ values that were not as high as those estimated using codes and standards during the design phase, suggesting that current design codes and standards may well be overly conservative. Codes and standards yield values based on the assumptions of intrinsic and extrinsic parameters. While literature on the subject lists a variety of factors that determine the thermal characteristic of a concrete mix, readily used design codes focus on only a selected few of these factors (binder content, binder type, section thickness and type of formwork), while seemingly neglecting others (coarse aggregate type, coarse aggregate size, placing temperature, sequence of construction and distribution of movement joints). It is the role of these factors that could be more significant than previously anticipated. Based on the findings discussed and summarised in this paper, the following recommendations are made to further this study:

- Subsequent studies into the subject should be conducted with equipment that makes the logging, recording and capturing of data more practical and accessible. Further research into temperature measurement and monitoring in concrete should not exclude options that can be costlier due to the incorporation of latest technologies in their usage e.g. wireless sensory sacrificial probes instead of thermocouple wiring.

- Experimental programmes that are compiled for future studies should aim to incorporate a wider variety of intrinsic and extrinsic factors so that the influence of each factor on the thermal properties of concrete can be assessed/quantified in terms of a specific set of criteria. One could achieve this by possibly isolating one factor at a time and begin building up a data base of different binary/ternary blended mixes with different binder contents, binder types, w/b ratios, aggregate types/sizes, as well as variable on-site practices (curing methods, different formwork-stripping times etc.) This would enable the Engineer/Contractor to see which of these factors has the most significant influence on the thermal behaviour of a specific concrete mix, and to thus make the necessary decisions during design and 
construction to offset the detrimental effects of cracking.

The author wishes to acknowledge the following people's contributions to the research and compilation of the paper, as well as for their continuous support throughout the study:

- Mr Dries van Taak and Mr Shane Roach (Stellenbosch Municipality).

- Mr Dawid Malan (Aurecon).

- Mr Cobus Le Roux, Mr Piet Wessels and Mr Alex Pospech (CSV Construction).

- Mr George Evans (PPC).

- Prof. Mark Alexander (CoMSIRU, UCT).

- Dr Peter Graham (School of Civil and Environmental Engineering, WITS University).

- Mr Tony Smith (AWR Smith Process Instrumentation).

- Mr Jerry van Loggerenberg (Thermocouple Products (Pty) Ltd).

\section{References}

1. J. Gajda, M. Vangeem, Concr. Int. J. 1, 59-62 (2002).

2. Various, Design Manual for Roads and Bridges 1, 111 (1987).

3. B. Klemczak, A. Knoppik-Wrobel, Arch. Civ. Eng. Env. J., 2, 35-48 (2011).

4. B. Klemczak, A. Knoppik-Wrobel, Arch. Civ. Eng. Env. J., 3, 35-70 (2011).
5. Y. Ballim, P.C. Graham, School of Civil and Environmental Engineering, University of Witwatersrand, published by the Dept of Civil Eng., UCT (2004).

6. C. Stanley, Unibeton Ready Mix Presentation (2009).

7. Various, NRMCA, 42 (2009).

8. Various, Holderchem, S1v1, 1-3 (2012).

9. Various, Concr. Tech. Today, 18, 1-8 (1997).

10. P.B. Bamforth, CIRIA C660 Early-age thermal crack control in concrete, 1-23 (2007).

11. Various, BS 8007, British Standards Institute (1987).

12. P.C. Graham, Report - Concrete heat of hydration test, School of Civil and Environmental Engineering (2016).

13. G.J. Gibbon, Y. Ballim, G.R.H. Grieve, Journal of Testing and Evaluation, 25, 2 (1997).

14. M.G. Alexander, H. Jaufeerally, J.R. Mackechnie, University of Cape Town and University of Canterbury, published by the Dept of Civil Eng., UCT (2003).

15. G. Grieve, Fulton's Concrete Technology Ninth Edition, Chapter 3, C\&CI (2009).

16. P.C. Graham, Y. Ballim, Magazine of Concrete Research, 55, 249-256 (2003). 